\title{
8
}
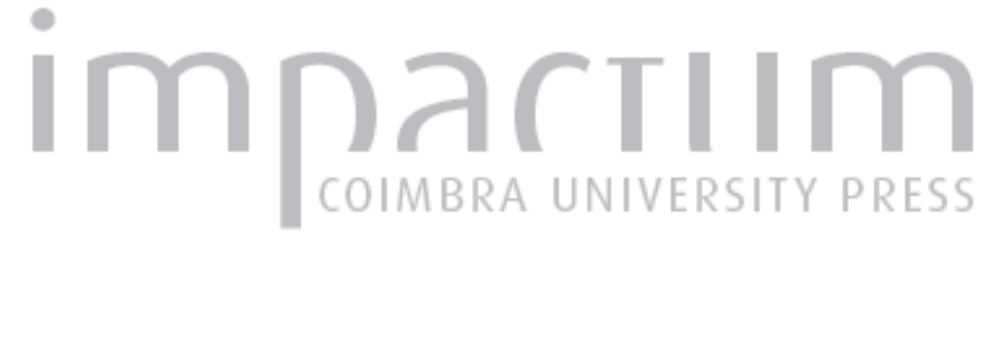

\section{Roman Sexuality: Images, Myths and Meanings}

\section{Autor(es): $\quad$ Santos, Nídia Catorze}
Publicado por: Associação Portuguesa de Estudos Clássicos; Instituto de Estudos Clássicos

URL persistente:

URI:http://hdl.handle.net/10316.2/30364

DOI:

DOI:http://dx.doi.org/10.14195/0872-2110_55_15

Accessed : $\quad$ 26-Apr-2023 00:42:48

A navegação consulta e descarregamento dos títulos inseridos nas Bibliotecas Digitais UC Digitalis, UC Pombalina e UC Impactum, pressupõem a aceitação plena e sem reservas dos Termos e Condições de Uso destas Bibliotecas Digitais, disponíveis em https://digitalis.uc.pt/pt-pt/termos.

Conforme exposto nos referidos Termos e Condições de Uso, o descarregamento de títulos de acesso restrito requer uma licença válida de autorização devendo o utilizador aceder ao(s) documento(s) a partir de um endereço de IP da instituição detentora da supramencionada licença.

Ao utilizador é apenas permitido o descarregamento para uso pessoal, pelo que o emprego do(s) título(s) descarregado(s) para outro fim, designadamente comercial, carece de autorização do respetivo autor ou editor da obra.

Na medida em que todas as obras da UC Digitalis se encontram protegidas pelo Código do Direito de Autor e Direitos Conexos e demais legislação aplicável, toda a cópia, parcial ou total, deste documento, nos casos em que é legalmente admitida, deverá conter ou fazer-se acompanhar por este aviso.

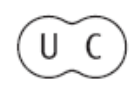




\section{Boletim de \\ Estudos Clássicos}

Associação Portuguesa de Estudos Clássicos

Instituto de Estudos Clássicos

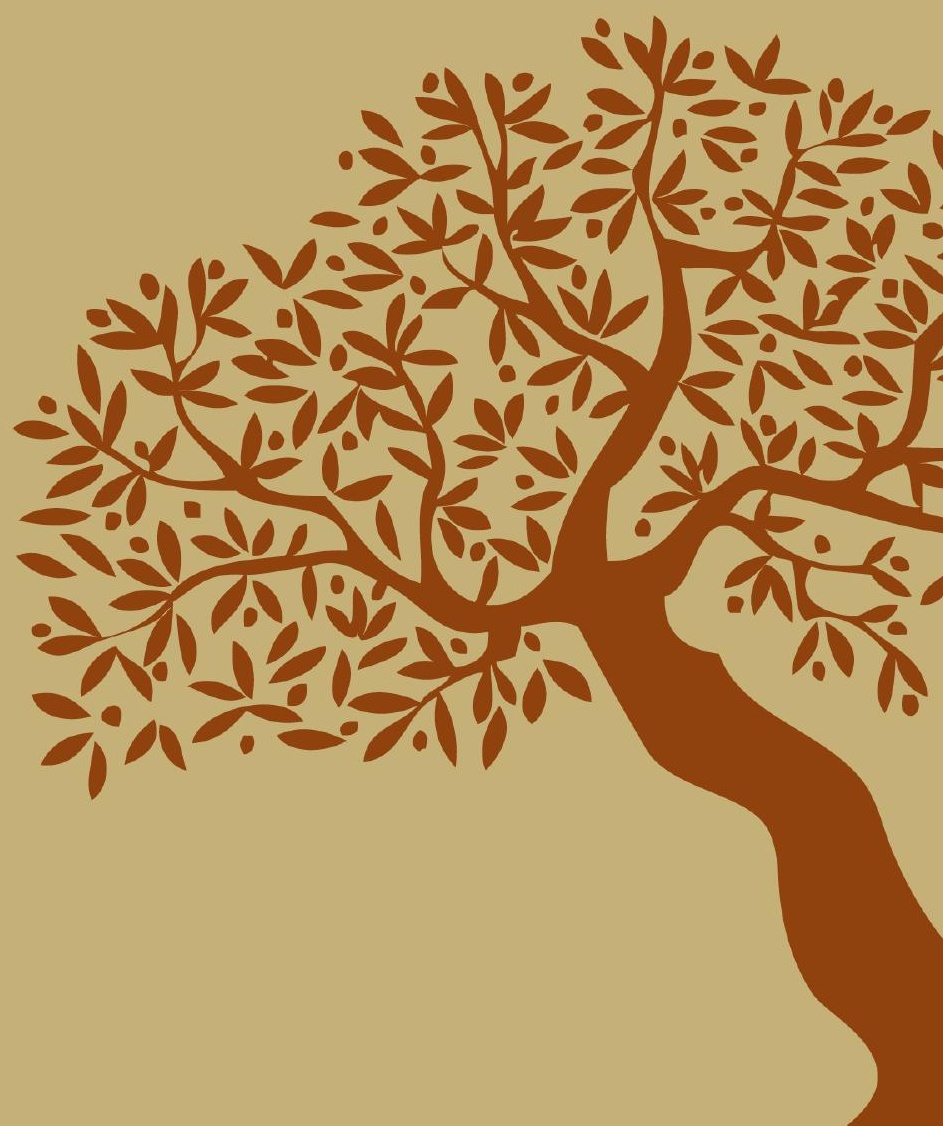

Coimbra

Junho de 2011 
State, o conferencista abordou a realização cultural dos monstros, a sua divulgação e disseminação com a emergência das primeiras cidades, estados e elites no Próximo Oriente há cinco mil anos. Ainda que muito centradas nas realidades próximo-orientais e no mediterrâneo oriental, foram naturalmente tidas em consideração outras regiões como a China da Idade do Bronze e a Europa Medieval.

Longe de ser um capítulo encerrado na longa história da humanidade, a História Antiga mostra através destas iniciativas, que vários temas permanecem em aberto, o contributo que a interdisciplinaridade pode ter na abordagem das temáticas e acima de tudo a saúde de uma disciplina cuja morte já foi por diversas vezes anunciada.

NÍDIA CATORZE SANTOS

\section{ROMAN SEXUALITY: IMAGES, MYTHS AND MEANINGS}

$\mathrm{Na}$ Weston Gallery, Lakeside Art Center, Notthingham (Inglaterra), esteve patente ao público, de 14 de Janeiro a 10 de Abril do corrente ano, a exposição Roman Sexuality: Images, Myths and Meanings, com a participação de objectos pertencentes ao Museu Britânico, Museus de Nottingham e ainda ao Museu de Arqueologia e Antropologia de Cambridge, sob a direcção de Clare Pickersgill, do Museu da Universidade de Nottingham e Paul Roberts do Museu Britânico. Com uma temática apelativa para o grande público e apoiada também pelo desenvolvimento e divulgação que os estudos promovidos pelos Gender Studies conheceram nos últimos anos, a exposição reuniu uma grande variedade de objectos eróticos romanos na tentativa de compreender qual o significado que tinham para os fabricantes e para os compradores. Muitos dos artefactos em exposição, como vasos, taças, pendentes, lamparinas e mesmo brincos infantis, apresentam o falo como elemento decorativo e torna-se assim claro que, à época, não teriam a carga sexual que hoje lhes atribuímos e, em vez disso, assumiam um carácter protector, benfazejo, de fertilidade ou mesmo humorístico. De realçar que conceitos como o amor religioso e profano, deuses, deusas e mitos associados à sexualidade também não ficaram esquecidos. 


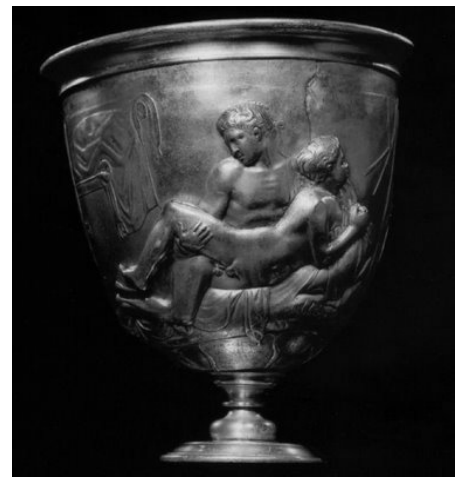

Logo no início da mostra, o público foi confrontado com o modo como a mentalidade vitoriana acabou por moldar a forma como estes artefactos foram coleccionados, expostos e estudados. Muitos deles foram censurados e permaneceram décadas nos armazéns dos museus. A Taça Warren (séc. I A.D.), a jóia da coroa desta exibição e fundamental para a discussão da sexualidade romana, é, um dos melhores exemplos desta situação. De prata, originária de Bittir, perto de Jerusalém, e decorada com cenas de amor homoeróticas, permaneceu durante décadas nas mãos de coleccionadores privados devido à natureza das mesmas, e só foi exposta ao público nos anos 80 do século passado, graças à mudança de mentalidades entretanto ocorrida. Foi precisamente à Taça Warren que duas das três conferências que acompanharam esta mostra foram dedicadas. A primeira dedicada a E. P. Warren, o coleccionador que lhe deu o nome e o seu círculo de amigos, enquanto a segunda a integrou na sociedade romana do seu tempo. A última conferência foi dedicada à forma feminina da escultura britânico-romana.

Esta iniciativa não se ficou por aqui e estava planeado um simpósio no Lakeside Arts Center da Universidade de Nottingham, a decorrer no dia 15 de Março e onde quatro temáticas abrangentes: a psicologia da sexualidade, história social da sexualidade, política e sexualidade e ainda atitudes passadas perante a sexualidade e a sua influência na percepção moderna dos objectos e imaginário, estruturam as comunicações dos participantes, vindos das mais diversas áreas, entre as quais estudos clássicos, arqueologia, música, arte ou história social.

NÍDIA CATORZE SANTOS 